Azucena Bautista

Hernández ${ }^{1}$

Enrique de Vega-Ríos'

Jorge Serrano Ballesteros ${ }^{1}$

Daniel Useros Braña ${ }^{1}$

Laura Cardeñoso Domingo ${ }^{2}$

Angels Figuerola Tejerina ${ }^{3}$

Andrés von Wernitz Teleki ${ }^{4}$

David Jiménez Jiménez ${ }^{5}$

Ignacio de los Santos Gil'

Carmen Sáez Béjar'

\section{Impact of the implementation of a Sepsis Code Program in medical patient management: a cohort study in an Internal Medicine ward}

\author{
IInternal Medicine and Infectious Diseases Department. Hospital de la Princesa, IIS-IP, Madrid, Spain. \\ ${ }^{2}$ Microbiology department, Hospital de la Princesa, IIS-IP, Madrid, Spain. \\ ${ }^{3}$ Preventive Medicine department, Hospital de la Princesa, IIS-IP, Madrid, Spain. \\ ${ }^{4}$ Emergency department, Hospital de la Princesa, IIS-IP, Madrid, Spain. \\ ${ }^{5}$ Intensive Care department. Hospital de la Princesa, IIS-IP, Madrid, Spain.
}

Article history

Received: 19 September 2021; Revision Requested: 5 October 2021; Revision Received: 5 October 2021;

Accepted: 4 November 2021; Published: 31 January 2022

\section{ABSTRACT}

Introduction. Sepsis is the main cause of death in hospitals and the implementation of diagnosis and treatment bundles has shown to improve its evolution. However, there is a lack of evidence about patients attended in conventional units.

Methods. A 3-year retrospective cohort study was conducted. Patients hospitalized in Internal Medicine units with sepsis were included and assigned to two cohorts according to Sepsis Code (SC) activation (group A) or not (B). Baseline and evolution variables were collected.

Results. A total of 653 patients were included. In 296 cases SC was activated. Mean age was 81.43 years, median Charlson comorbidity index (CCI) was 2 and $63.25 \%$ showed some functional disability. More bundles were completed in group A: blood cultures $95.2 \%$ vs $72.5 \%(p<0.001)$, extended spectrum antibiotics $59.1 \%$ vs $41.4 \%(p<0.001)$, fluid resuscitation $96.62 \%$ vs $80.95 \%(p<0.001)$. Infection control at 72 hours was quite higher in group A ( $81.42 \%$ vs $55.18 \%$, odds ratio 3.55 [2.48-5.09]). Antibiotic was optimized more frequently in group A (60.77\% vs 47.03\%, $p$ 0.008). Mean in-hospital stay was 10.63 days ( 11.44 vs 8.53 days, $p<0.001$ ). Complications during hospitalization appeared in $51.76 \%$ of patients, especially in group B (45.95\% vs 56.58\%, odds ratio 1.53 [1.122.09]). Hospital readmissions were higher in group $A$ (40\% vs $24.76 \%, p<0.001)$. 28-day mortality was significantly lower in group A (20.95\% vs $42.86 \%$, odds ratio 0.33 [0.23-0.47]).

Conclusions. Implementation of SC seems to be effective in improving short-term outcomes in IM patients, although therapy should be tailored in an individual basis.

Keywords: Sepsis, Internal Medicine, short-term mortality, complications, readmissions

Correspondence:

Azucena Bautista Hernández

Internal Medicine Clinician, Hospital Universitario de La Princesa.

C/Diego de León, 62 - 28006. Madrid, Spain.

E-mail: bautistazucena@gmail.com
Impacto de la implementación del Programa Código Sepsis en una planta de hospitalización médica: estudio de una cohorte de pacientes de Medicina Interna

\section{RESUMEN}

Introducción. La sepsis es la principal causa de muerte en los hospitales y la implantación de códigos para su manejo ha demostrado mejorar su evolución. Sin embargo, es escasa la evidencia relativa a los pacientes atendidos en unidades médicas convencionales.

Métodos. Se realizó un estudio de cohortes retrospectivo de 3 años. Se incluyeron pacientes con sepsis hospitalizados en unidades de Medicina Interna y se asignaron a dos cohortes según la activación del Código Sepsis (CS) (grupo A) o no (B). Se recogieron variables basales y de evolución.

Resultados. Se incluyeron 653 pacientes. En 296 casos se activó el SC. La edad media fue de 81,43 años, la mediana del indice de comorbilidad de Charlson (ICC) fue de 2 y el 63,25\% presentaba alguna limitación funcional. Se realizaron más acciones diagnósticas y terapéuticas en el grupo A: hemocultivos $95,2 \%$ vs $72,5 \%(p<0,001)$, antibióticos de espectro extendido $59,1 \%$ vs $41,4 \%(p<0,001)$, reanimación con líquidos $96,62 \%$ vs $80,95 \%(p<0,001)$. El control de la infección a las 72 horas fue superior en el grupo A $(81,42 \%$ vs $55,18 \%$, odds ratio 3,55 $[2,48-5,09])$. La optimización de los antibióticos fue más frecuente en el grupo A (60,77\% vs 47,03\%, p 0,008). La estancia media en el hospital fue de 10,63 dias $(11,44$ vs 8,53 dias, $p<$ $0,001)$. Aparecieron complicaciones durante la hospitalización en el $51,76 \%$ de los pacientes, especialmente en el grupo B $(45,95 \%$ vs $56,58 \%$, odds ratio $1,53[1,12-2,09])$. Los pacientes del grupo A reingresaron más ( $40 \%$ vs $24,76 \%, p<0,001$ ). La mortalidad a los 28 días fue significativamente menor en el grupo A (20,95\% frente a 42,86\%, odds ratio 0,33 $[0,23-0,47])$.

Conclusiones. La aplicación del CS parece ser eficaz para 
mejorar los resultados a corto plazo en los pacientes de MI, aunque el tratamiento debe adaptarse de forma individual.

Palabras clave: Sepsis, Medicina Interna, mortalidad corto plazo, complicaciones, reingresos

\section{INTRODUCTION}

Sepsis is the leading cause of death in hospitals in Spain and its incidence and mortality is constantly increasing in developed countries [1-7]. The fatality rate associated with sepsis is higher than 10\% and higher than other serious medical entities, reaching $40 \%$ in cases of septic shock $[1,2]$.

Prognosis of sepsis and septic shock is related to the time elapsed between the onset of symptoms and the administration of antibiotics and fluid resuscitation $[5,8]$. In recent decades, various initiatives have shown that early and organized detection and treatment of sepsis, reduce mortality by up to $50 \%(3,4,9,10]$. In our country, the Sepsis code protocol (SCP) has been endorsed by the main scientific societies [11,12]. In this context, a multidisciplinary team was formed in our hospital in 2013. Its objective was to develop, promote and update a protocol to improve the prognosis of patients with sepsis, not only those admitted to the Intensive Care Unit (ICU), but also patients in conventional wards. Our guide established some key elements for sepsis management, focusing on diagnosis, biomarkers and therapy. It was based on the compendium of recommendations or bundles published by the Surviving Sepsis Campaign $[9,13]$, among others. This SC initiative was implemented in the hospital's clinical practice in 2015

Most of the evidence on the impact of these early detection and management packages on sepsis patients comes from those hospitalized in the ICU [1-5]. This group of individuals usually share some characteristics such as age under 80 years, preserved functional capacity and absence of severe baseline comorbidity that could determine their survival prognosis. However, the clinical setting in conventional hospital units is different, especially in the case of Internal medicine (IM): the range of patients is broader including those with greater comorbidity, age or functional dependence $[14,15]$. Currently, there is limited evidence on how bundles affect the clinical course of these patients, who account for at least 50\% of sepsis diagnoses in hospitals $[16,17]$. Furthermore, despite protocol implementation, we identify a significant number of patients in whom the code is not activated at the time of sepsis diagnosis. We think it could be related to a worse baseline situation due to relevant comorbidities or cognitive impairment. In addition, literature has recently emerged offering contradictory findings about potential negative impact of implementing certain aspects of the SCP such as excessive or rigid fluid resuscitation [18-22]. Therefore, we considered it necessary to develop a research line to explore the best management options for this hugely diverse group of patients.

Accordingly, the main aim of this study was to evaluate the impact of the Sepsis Code (SC) on the morbidity and mortality of sepsis patients outside the ICU to identify potentially improvable points. The SC program included the main recommendations of the current SSC guidelines [9] regarding the diagnosis, treatment and follow-up of sepsis. For that purpose, we describe and analyze, in patients hospitalized at the IM ward, the baseline and evolutionary differences between patients managed with and without activated SC.

\section{PATIENTS AND METHODS}

Patients. This was a retrospective study conducted at the IM unit of Hospital Universitario de La Princesa (HULP), a tertiary teaching center in Madrid (Spain), from January 2016 to December 2018. The entire hospital has roughly $15000 \mathrm{ad}-$ missions per year and the IM Department around 2200. This study was approved by the Research ethics Committee of the hospital (protocol number: 3703).

All patients hospitalized at the IM ward as the first location and with a diagnosis, in the clinical discharge report, of sepsis or any septic-related presentation according to ICD-10CM [23] were eligible. We checked if the SC alert had been activated in those patients hospitalized in $\mathrm{Ml}$ during the study period. For this purpose, the documentation department has a list of all historically activated alerts in the hospital. The sample was divided into two cohorts according to whether SC was activated (A) or not (B). The only exclusion criterion was to have been initially admitted to other department. In addition, we included in cohort A those patients who lacked a sepsis or related diagnosis in the discharge report but were managed with an activated SC during hospitalization. The diagnosis and treatment protocol in cohort $\mathrm{A}$ was based on the bundles recommended in the current SSC guidelines [9] and on usual care in cohort B.

Data collection. The following baseline demographic and clinical characteristics collected from the medical information system were included: age, gender, comorbidities, immunosuppression, risk factors for developing a multidrug-resistant bacterial (MDRB) or a fungal infection, presence and type of devices, functional capacity, site of infection, presence of third space enlargement defined as pleural effusion, leg edema or ascites, and evidence of some abscess. All of them referred to the situation at the time of hospital admission, which usually coincided with sepsis diagnosis. Comorbidity burden was assessed using the Charlson comorbidity index (CCI). We considered relevant comorbidity if $\mathrm{CCl}$ was $>3$ as previous reports [24-27]. Functional capacity was evaluated using the Barthel Index (BI) $[28,29]$ and was classified into three ranges: independence $\geq 99$ points, partial dependence $30-98$ points and severe dependence $\leq 29$ points.

The type, number, and time of sampling for the microbiology laboratory were reviewed. Also, variables related to antibiotic treatment, surgical or interventionist control of the infectious site, fluid resuscitation, vasopressors, blood transfusions, and corticoid therapy were collected. Data on time to fluid resuscitation from diagnosis of sepsis and activation of SC were only available for patients in group $A$. 
Outcome measures. The primary outcome was 28-day mortality rate. Other outcomes included were: 1) controlled infection within 72 hours from diagnosis, defined as the absence of fever, hemodynamic stability and improvement of acute phase reactants (drop in leukocytes, C-reactive protein or procalcitonin), 2) overall length of the stay, 3) in-hospital complications; 4) detrimental effects of antibiotic, 5) readmission within the following 12 months and its causes, and 6) in-hospital and long-term mortality (at 365 days).

Statistical analysis. Results are expressed as means and standard deviation (SD), medians and interquartile range (IQR), or proportions with 95\% confidence intervals (CI) as appropriate. $\chi^{2}$ test or Fisher's exact test were used to compare categorical variables and Student's $t$-test or Mann-Whitney U test to compare continuous variables. The cumulative incidence of mortality was estimated using the Kaplan-Meier method and compared using the log-rank test. We examined factors associated with outcomes by conducting logistic regression. All statistical analyses were performed using SPSS software (version 25). Two- tailed $p$ values $\leq 0.05$ were considered statistically significant.

\section{RESULTS}

Baseline characteristics. A total of 653 patients out of 6.676 admitted to the IM ward during the study period were included, as shown Figure 1. Of them, 564 patients were diagnosed with sepsis or any related form in the medical discharge report, while 89 patients did not have sepsis diagnosis but were managed with activated SC. The total of diagnosed patients was divided into two cohorts according to whether the SC was activated (cohort A, 296 patients) or not (cohort B, 357 patients).

Patients in cohort B were older (83.05 vs 79.32 years, $p$ $=0.001)$ and their functional status was worse than those in cohort A (severe dependent patients $41.46 \%$ vs $27.36 \%, p<$ $0.001)$. The presence of comorbidity and the distribution of infection foci did not differ between cohorts, whereas the presence of third space enlargement was numerically greater in cohort $B(p=0.056)$.

Characteristics of microbiological diagnosis and treatment. The differences in timing and details of sample collection for microbiological diagnosis are summarized in Table 2. More samples were collected in cohort A (98.31\% vs

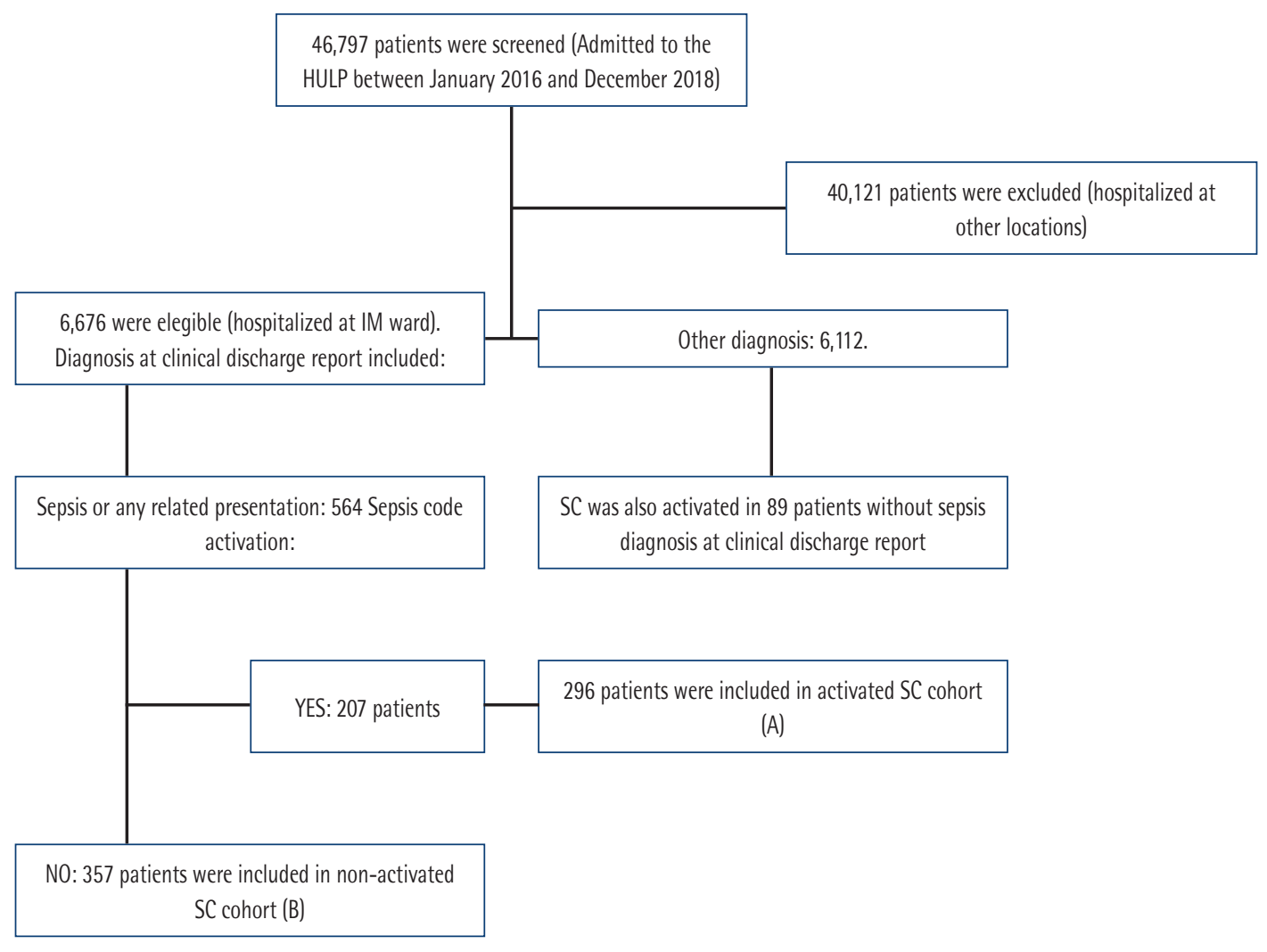

\begin{tabular}{|l|l}
\hline Figure 1 & Study flowchart.
\end{tabular} 


\begin{tabular}{|c|c|c|c|c|c|}
\hline \multirow{3}{*}{\multicolumn{2}{|c|}{\begin{tabular}{l|l} 
Table 1 & Baseline and clinical characteris \\
Baseline and clinical characteristics
\end{tabular}}} & \multirow{3}{*}{$\begin{array}{l}\text { TOTAL } \\
n=653\end{array}$} & \multirow{3}{*}{$\begin{array}{c}\text { SC activated (A) } \\
n=296\end{array}$} & \multirow{3}{*}{$\begin{array}{c}\text { SC not activated (B) } \\
n=357\end{array}$} & \multirow{3}{*}{ p } \\
\hline & & & & & \\
\hline & & & & & \\
\hline \multicolumn{2}{|c|}{ Age, years mean (SD) } & $81.43(14.60)$ & $79.32(15.31)$ & $83.05(13.78)$ & 0.001 \\
\hline \multicolumn{2}{|c|}{ Male sex, $n(\%)$} & 311 & $160(54.05)$ & $151(42.3)$ & 0.003 \\
\hline \multicolumn{2}{|c|}{ Charlson comorbidity index, median (IOR) } & $2(1-4)$ & $2(1-4)$ & $2(1-4)$ & 0.11 \\
\hline \multicolumn{2}{|c|}{ Charlson comorbidity index $>3, n(\%)$} & $283(43.3)$ & $119(40.2)$ & $164(45.9)$ & 0.141 \\
\hline \multicolumn{2}{|c|}{ Inmmunosuppression, $\mathrm{n}(\%)$} & $74(11.33)$ & $41(13.85)$ & $33(9.24)$ & 0.064 \\
\hline \multicolumn{2}{|c|}{ Risk factors for multi-resistant bacterial infection, $n(\%)$} & $298(45.64)$ & $152(51.35)$ & $146(40.9)$ & 0.008 \\
\hline \multicolumn{2}{|c|}{ Risk factors for fungal infection, $n(\%)$} & $153(23.43)$ & $80(27.03)$ & $73(20.45)$ & 0.048 \\
\hline \multicolumn{2}{|c|}{ Device carrier, n (\%) } & $74(11.3)$ & $36(12.2)$ & $38(10.6)$ & 0.542 \\
\hline \multicolumn{2}{|c|}{ Type of device, $n(\%)$} & & & & 0.321 \\
\hline \multicolumn{2}{|c|}{ Bladder catheter } & $55(74.3)$ & $25(69.4)$ & $30(78.9)$ & \\
\hline \multicolumn{2}{|c|}{ Another urinary catheter } & $6(8.1)$ & $2(5.6)$ & $4(10.5)$ & \\
\hline \multicolumn{2}{|c|}{ Nasogastric tube } & $9(12.2)$ & $7(19.4)$ & $2(5.3)$ & \\
\hline \multicolumn{2}{|c|}{ Digestive endoprosthesis } & $2(2.7)$ & $1(2.8)$ & $1(2.6)$ & \\
\hline \multicolumn{2}{|c|}{ Both, bladder catheter and nasogastric tube } & $1(1.4)$ & $1(2.8)$ & $0(0)$ & \\
\hline \multicolumn{2}{|c|}{ Ventriculoperitoneal system } & $1(1.4)$ & $0(0)$ & $1(2.6)$ & \\
\hline \multicolumn{2}{|c|}{ Functional capacity, n (\%) } & & & & 0.001 \\
\hline \multicolumn{2}{|c|}{ Independence } & $240(36.75)$ & $124(41.89)$ & $116(32.49)$ & \\
\hline \multicolumn{2}{|c|}{ Partial dependence } & $184(28.18)$ & $91(30.74)$ & $93(26.05)$ & \\
\hline \multicolumn{2}{|c|}{ Severe dependence } & $229(35.07)$ & $81(27.36)$ & $148(41.46)$ & $<0.001$ \\
\hline \multicolumn{3}{|c|}{ Suspected site of infection, $\mathrm{n}(\%)$} & & & 0.189 \\
\hline \multicolumn{2}{|c|}{ Neurologic } & $4(0.61)$ & $2(0.64)$ & $2(0.56)$ & \\
\hline \multicolumn{2}{|c|}{ Pulmonary } & $219(33.54)$ & $93(31.42)$ & $126(35.29)$ & 0.296 \\
\hline \multicolumn{2}{|c|}{ Urinary tract } & $258(39.51)$ & $112(37.84)$ & $146(40.9)$ & 0.426 \\
\hline Both, puln & and urinary tract & $34(5.21)$ & $13(4.39)$ & $21(5.88)$ & \\
\hline Abdomina & & $36(5.5)$ & $19(6.4)$ & $17(4.8)$ & \\
\hline Soft tissue & & $49(7.5)$ & $24(8.1)$ & $25(7)$ & \\
\hline Intravascu & & $3(0.5)$ & $3(1)$ & 0 & \\
\hline Surgical si & & $1(0.2)$ & $0(0)$ & $1(0.3)$ & \\
\hline Orthopedi & & $12(0.3)$ & $1(0.3)$ & $1(0.3)$ & \\
\hline Unknown & & $47(7.2)$ & $29(9.8)$ & $18(5)$ & \\
\hline Concordance & en suspected and confirmed infection site, $n(\%)$ & $515(78.9)$ & $228(77)$ & $287(80.4)$ & 0.294 \\
\hline Third space el & nent, $n(\%)$ & $52(7.96)$ & $17(5.74)$ & $35(9.8)$ & 0.056 \\
\hline Abscess, $n(\%$ & & $39(5.97)$ & $14(4.73)$ & $25(7)$ & 0.248 \\
\hline
\end{tabular}

Significant $p$ values $(\leq 0.05)$ are highlighted in bold. Abbreviations: IQR, interquartile range; $S C$, Sepsis Code; $S D$, standard deviation

82.07\%, $p<0.001)$, especially blood samples (95.2\% vs 72.5\%, $p<0.001)$. On the contrary, urine culture was more frequently collected in cohort B ( $p$ 0.015).

Regarding treatment, extended-spectrum antibiotic was more frequent in group A (59.1\% vs 41.4\%, $p<0.001)$ and antibiotic treatment was also changed more frequently in this cohort ( 61.1 vs $53.5 \%, p 0.046)$, especially in relation to microbiological results $(60.77 \%$ vs $47.03 \%, p 0.008)$. There were also significant differences in the number of patients who received 

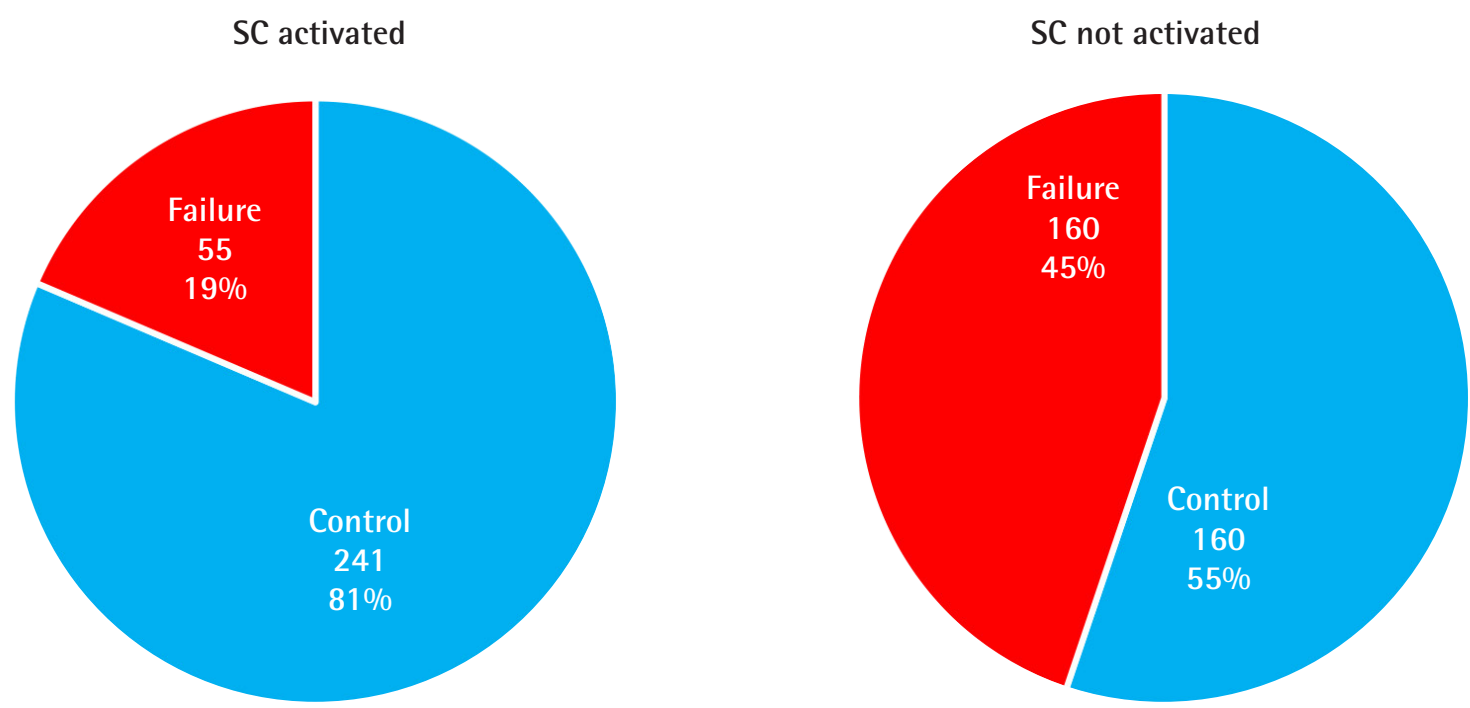

\section{Figure 2 Infection status within 72 hours from diagnosis. Data are expressed as $\mathrm{n}$ and $\%$ in the two cohorts.}

SC: Sepsis Code.

fluid resuscitation $(96.62 \%$ vs $80.95 \%, p<0.001)$ and vasopressors $(12.88 \%$ vs $1.4 \%, p<0.001)$. Time to fluid resuscitation in group A was less than 1 hour in 268 patients (93.71\%).

Clinical evolution. Sepsis was controlled within 72 hours in $81.42 \%$ of patients in cohort $A$ in contrast to $55.18 \%$ in cohort B (OR 3.55, 95\% Cl 2.48-5.09, $p<0.001$ ) as shown in Figure 2.

Patients with activated SC stayed longer in hospital (11.44 days vs 8.53 days, $p<0.001)$ and received longer-lasting antibiotic treatments ( 12.46 days vs 8.26 days, $p=0.003$ ). However, time to narrow the spectrum of antibiotics was longer in cohort $B$ ( 2.31 days vs 4.13 days, $p=0.017$ ). No differences in the time to hospital readmission could be found between the two cohorts (Table 3).

Complications during hospitalization are summarized in Table 4 and Figure 3. Remarkably, overall number of complications was higher in cohort B (45.95\% vs $56.58 \%$, OR $1.53,95 \%$ $\mathrm{Cl} 1.12-2.09, p 0.007)$, as well as acute renal failure (0.7\% vs $6.4 \%$, OR $0.0995 \% \mathrm{Cl} 0.02-0.42, p<0.001$ ) and others globally (10.1\% vs 32.2\%, OR 0.23 95\% Cl 0.15-0.36, $p<0.001)$. Conversely, the incidence of heart failure and acute confusional episodes was significantly higher in cohort A (27.36\% vs 19.05 and $47.2 \%$ vs $27.2 \% p<0.001$, respectively).

Side effects after antibiotic treatment are shown in Table 5 and Figure 4. No statistically significant differences in the appearance of toxicity could be found between cohorts, whereas the incidence in the following year of infections by MDRB was higher in cohort B (OR 0.15,95\% Cl 0.03-0.76, p 0.012 ). However, readmissions were more frequent in cohort $A$ (OR 2.02, 95\% Cl 1.36-2.99, $\mathrm{p}<0.001)$ and the leading cause was another infection or sepsis (Table 6).

Mortality. Mortality information is shown in Figure 5. 28day and in-hospital mortality were lower in cohort A (18.92\% vs $37.54 \%$, OR $0.3995 \% \mathrm{Cl} 0.27-0.55, p<0.001$ and $20.95 \%$ vs 42.86\%, OR 0.23-0.47 95\% Cl 0.23-0.47, $p<0.001$, respectively). Conversely, at 365 days mortality reached $58.8 \%$ in cohort $A$ vs $40.3 \%$ in B (OR 1.5 95\% Cl 1.00-2.25, p 0.045). Differences between 28-day survival curves are shown in Figure 6. Highlights the difference in mortality especially in the short term.

\section{DISCUSSION}

Baseline characteristics and sepsis diagnosis. Patients in our sample had an overall average age higher than that referred in the European series (around $70-75$ years) [30-32]. The difference is even greater compared with cohort B. Our average age can be compared with that shown by Vardi et al. [33] and Liu et al. [34], from their elderly subgroup.

Regarding comorbidities, the overall median $\mathrm{CCl}$ and the percentage of patients with immunosuppression, did not differ between cohorts and were similar to those of reference series $[33,35]$. It is notable that half of patients had risk factors for MDRB infection. More than half had a deteriorated functional status and a third showed severe deterioration. There are significant differences between groups, with a worse functional status in no-SC group. We consider that this could be one of the criteria (along with age) for SC activation, since the rest of the baseline characteristics are similar in both groups.

Most infections appeared at the pulmonary and urinary tracts in both cohorts and showed a low rate of abscesses, pre- 


\begin{tabular}{|c|c|c|c|c|c|}
\hline Table 2 & \multicolumn{5}{|c|}{ Characteristics of microbiological diagnosis and treatment. } \\
\hline \multicolumn{2}{|c|}{ Microbiological diagnosis and treatment } & Total & SC activated (A) & SC not activated (B) & p \\
\hline \multicolumn{2}{|c|}{ Samples collected for microbiology, $n(\%)$} & $584(89.13)$ & $291(98.31)$ & $293(82.07)$ & $<0.001$ \\
\hline \multicolumn{2}{|c|}{ At least two different samples collected, $n(\%)$} & $448(68.61)$ & $255(86.15)$ & $193(54.06)$ & $<0.001$ \\
\hline \multicolumn{2}{|c|}{ Blood sample, $n(\%)$} & $488(83.8)$ & $277(95.2)$ & $211(72.5)$ & $<0.001$ \\
\hline \multicolumn{2}{|c|}{ Urine sample, $n(\%)$} & $398(68.3)$ & $185(63.6)$ & $213(72.9)$ & 0.015 \\
\hline \multicolumn{2}{|c|}{ Abdominal exudate or drainage, $n(\%)$} & $16(2.7)$ & $8(2.7)$ & $8(2.7)$ & 1,000 \\
\hline \multicolumn{2}{|c|}{ Other samples, $n(\%)$} & & & & 0.397 \\
\hline \multicolumn{2}{|c|}{ Respiratory tract exudate } & $50(64.9)$ & $6(66.7)$ & $44(64.7)$ & \\
\hline \multicolumn{2}{|c|}{ Soft tissue sample } & $15(19.5)$ & $1(11.1)$ & $14(20.6)$ & \\
\hline \multicolumn{2}{|c|}{ Cerebrospinal fluid } & $5(6.5)$ & 0 & $5(7.4)$ & \\
\hline \multicolumn{2}{|l|}{ Stool sample } & $7(9.1)$ & $2(22.2)$ & $5(7.4)$ & \\
\hline \multicolumn{2}{|c|}{ Collection previous to antibiotic administration, $n(\%)$} & $496(84.93)$ & $251(86.25)$ & $245(83.62)$ & 0.214 \\
\hline \multicolumn{2}{|c|}{ Extended spectrum antibiotic administration, $n(\%)$} & $317(49.6)$ & $175(59.1)$ & $142(41.4)$ & $<0.001$ \\
\hline \multicolumn{2}{|c|}{ Combination antibiotic therapy, $\mathrm{n}(\%)$} & $444(69.5)$ & $153(51.7)$ & $291(84.8)$ & $<0.001$ \\
\hline \multicolumn{2}{|c|}{ Intravenous antibiotic administration, $\mathrm{n}(\%)$} & $634(99.4)$ & $294(99.7)$ & $340(99.1)$ & 0.393 \\
\hline \multicolumn{2}{|c|}{ Surgical or interventionist therapy $n(\%)$} & $25(3.8)$ & $10(3.4)$ & $15(4.2)$ & 0.585 \\
\hline \multicolumn{2}{|c|}{ Antibiotic adjustment during evolution, $n(\%)$} & $366(56.90)$ & $181(61.1)$ & $185(53.3)$ & 0.046 \\
\hline \multicolumn{2}{|c|}{ Spectrum of coverage narrowed, $n \%$ ) } & $221(34.4)$ & $140(47.3)$ & $81(23.3)$ & $<0.001$ \\
\hline \multicolumn{2}{|c|}{ Optimization of therapy based on microbiological results, $n(\%)$} & $197(53.83)$ & $110(60.77)$ & $87(47.03)$ & 0.008 \\
\hline \multicolumn{3}{|c|}{ Other reasons for tailoring antibiotic, $\mathrm{n}(\%)$} & & & 0.025 \\
\hline \multicolumn{2}{|c|}{ Empirical optimization based on clinical practice guidelines } & $90(53.25)$ & $45(63.38)$ & $45(45.92)$ & \\
\hline \multicolumn{2}{|c|}{ Empirical optimization due to clinical failure } & $79(46.75)$ & $26(36.6)$ & $53(54.1)$ & \\
\hline \multicolumn{2}{|c|}{ Switch to oral antibiotic, $n(\%)$} & $278(43.23)$ & $165(55.74)$ & $113(32.56)$ & $<0.001$ \\
\hline \multicolumn{2}{|c|}{ Fluid resuscitation, $n(\%)$} & $575(88.06)$ & $286(96.62)$ & 289 (80.95) & $<0.001$ \\
\hline \multicolumn{2}{|c|}{ Fluid choice, $n(\%)$} & & & & 0.371 \\
\hline \multicolumn{2}{|l|}{ Crystalloid } & $570(99.13)$ & $283(98.95)$ & 287 (99.31) & \\
\hline Colloid & & $1(0.17)$ & 0 & $1(0.35)$ & \\
\hline Both, crys & and colloid & $4(0.70)$ & $3(1.05)$ & $1(0.35)$ & \\
\hline Vasopressor u & & $43(6.6)$ & $38(12.88)$ & $5(1.4)$ & $<0.001$ \\
\hline Vasopressor c & $n(\%)$ & & & & 0.002 \\
\hline Dopamine & & $33(71.74)$ & $30(78.95)$ & $3(37.5)$ & \\
\hline Dobutamir & & $3(6.52)$ & $0(0)$ & $3(37.5)$ & \\
\hline Noradrena & & $9(19.57)$ & $7(18.42)$ & $2(25)$ & \\
\hline Phenyleph & & $1(2.17)$ & 1 (2.63) & $0(0)$ & \\
\hline Blood transfu & $n(\%)$ & $21(3.23)$ & $13(4.42)$ & $8(2.25)$ & 0.119 \\
\hline Corticoid the & $(\%)$ & $64(9.83)$ & $32(10.88)$ & $32(8.96)$ & 0.413 \\
\hline
\end{tabular}

Time to fluid resuscitation is only shown for group $A$, because the exact time of sepsis onset in group B was unknown. Significant $p$ values $(\leq 0.05)$ are highlighted in bold. Abbreviations: SC, Sepsis Code 


\begin{tabular}{|c|c|c|c|c|c|}
\hline Table 3 & Quantitative variables. & & & & \\
\hline \multicolumn{2}{|c|}{ Quantitative variables } & Total & SC activated (A) & SC not activated (B) & p \\
\hline \multicolumn{2}{|c|}{ Length of hospital stay in days, mean (SD) } & $8.51(10.63)$ & $12.63(11.44)$ & $5.10(8.53)$ & $<0.001$ \\
\hline \multicolumn{2}{|c|}{ Length of ICU stay in days, mean (SD) } & $8.5(6.86)$ & $6.2(4.32)$ & $10.14(8.15)$ & 0.350 \\
\hline \multicolumn{2}{|c|}{ Total duration of antibiotic treatment in days, mean (SD) } & $11.55(10.36)$ & $12.77(12.46)$ & $10.29(8.26)$ & 0.003 \\
\hline \multicolumn{2}{|c|}{ Time to reduce antibiotic spectrum coverage in days, mean (SD) } & $4.35(3.21)$ & $3.88(2.31)$ & $5.04(4.13)$ & 0.017 \\
\hline \multicolumn{2}{|c|}{ Time to switch from intravenous to oral antibiotic in days, mean (SD) } & $6.46(5.21)$ & $6.88(5.54)$ & $5.93(4.75)$ & 0.117 \\
\hline \multicolumn{2}{|c|}{ Time to hospital readmission in days, mean (SD) } & $105.98(97.89)$ & $103.46(97.77)$ & $107.85(98.53)$ & 0.741 \\
\hline \multicolumn{2}{|c|}{ Time to hospital readmission in days, median (IQR) } & $64.88(30.41-152.08)$ & $64.88(32.44-151.06)$ & $64.38(30.41-154.87)$ & 0.903 \\
\hline
\end{tabular}

Significant $p$ values $(\leq 0.05)$ are highlighted in bold. Abbreviations: ICU, Intensive Care Unit; IOR, interquartile range; SD, standard deviation; SC, Sepsis Code.

dictably in medical patients and similar to published evidence [35-37].

Microbiological diagnosis and treatment. Microbiological diagnosis efforts were significantly different in both groups: samples were more frequently collected in group $A$, and the number of samples, specifically blood samples were also superior in this cohort while urine culture were more frequently obtained in group B, probably reflecting the "less invasive" attitude in the second group. This finding has important implications for the correct antibiotic treatment and may affect the control and evolution of the infection [38-40]. The compliance with the diagnostic sepsis bundles in cohort A are considerably better than those described in previous series (20-50\%). [3,36,41,42].

Antibiotic and fluid therapy were administered in a similar proportion than described in previous studies in ICU patients (63-100\%), whereas the proportion of vasopressor or steroid administration was lower [27-100\% and $29.9-70 \%$, respectively) $[3,4,41]$ as expected in conventional wards.

Extended spectrum antibiotics (ESA) were more frequently administered in cohort $A$. We found that these patients had more risk factors for MDRB at admission. Although combined therapy was more common in group B maybe reflecting the need for achieving the same coverage with narrower spectrum drugs. Antibiotic therapy was adjusted to microbiological results in more cases in group A and time to reduce antibiotic spectrum coverage was shorter. Moreover, antibiotic treatment was switched to oral route more frequently, though not earlier. Nevertheless, we observed a higher mean duration of total antibiotic treatment in group A. Similar length in the context of SCP implementation is shown in other series in our country (a mean of 10.9 days in Pinilla et al. [43] and 13 days in Garcia-López et al. [44]). Furthermore, it has been suggested that antibiotic stewardship programs do not reduce total duration of therapy $[40,45,46]$ and there is an increasing evidence showing that an early antibiotic de-escalation based on microbiological results provides similar survival and outcomes to those of a longer and extended treatment regimen
$[22,39,40,47,48]$. Therefore, it seems that antibiotic treatment is generally more appropriate in the SC group, although the time to narrow spectrum could be improved. In our study, group $B$ developed more infections due to MDRB during the following year, and this could be related to suboptimal antibiotic de-escalation [49].

A higher number of patients were treated with fluid resuscitation and vasopressors in group A according to SCP recommendations. In both, the main choice were crystalloids and dopamine, respectively. We found no differences in blood transfusion or corticosteroid therapy between groups.

Clinical evolution. The probability of controlling infection after 72 hours of treatment was almost 4 times higher in SC group. We found no published evidence regarding concrete information on early clinical improvement status after SCP implementation. Infection control is directly related to improving prognosis and short-term mortality $[3,4,9,50]$. In our population, complications were frequently observed, in more than $50 \%$ of patients, similar to that described by Vardi et al. [33]. The risk of complications is 1.5 higher in group B. Global length of stay was similar to other reports $[4,37,42]$. Treatment was more intensive in group A especially fluid resuscitation and it could be the reason for the higher incidence of heart failure. Acute confusional syndrome was also higher in group A. We think that it could be explained by longer reality deprivation. On the contrary, renal failure and others were more frequent in group B, probably related to this "less invasive" management. These findings widely support the opinion of other authors regarding the flexibility of the management recommendations in some frail patients, adapting them to their individual basis $[18,19,21,22,51]$.

Finally, almost a third of survivors were readmitted within 12 months. The probability of readmission is twice more frequent in group $\mathrm{A}$. The mean time to readmission was similar in both groups. Half of them occurred in the first 3 months after discharge, which may suggest that they were related to complications of sepsis and its treatment. Readmission rates and causes within the first 90 days after discharge were similar to 


\begin{tabular}{|c|c|c|c|c|c|c|c|}
\hline Table 4 & \multicolumn{7}{|c|}{ In-hospital complications. } \\
\hline \multicolumn{2}{|c|}{ In-hospital complications } & TOTAL & SC activated (A) & SC not activated (B) & $\mathrm{OR}$ & $95 \% \mathrm{Cl}$ & $p$ \\
\hline \multicolumn{2}{|c|}{ Complication outcomes, n (\%) } & $338(51.76)$ & $136(45.95)$ & $202(56.58)$ & 1.53 & $1.12-2.09$ & 0.007 \\
\hline \multicolumn{2}{|c|}{ Heart failure, $n(\%)$} & $149(22.82)$ & $81(27.36)$ & $68(19.05)$ & 1.6 & $1.10-2.31$ & 0.012 \\
\hline \multicolumn{2}{|c|}{ Phlebitis associated to intravenous catheters, $n(\%)$} & $24(3.68)$ & $9(3.04)$ & $15(4.2)$ & 0.75 & $0.30-1.65$ & 0.432 \\
\hline \multicolumn{2}{|c|}{ Acute renal failure, $n(\%)$} & $25(3.8)$ & $2(0.7)$ & $23(6.4)$ & 0.09 & $0.023-0.423$ & $<0.001$ \\
\hline \multicolumn{2}{|c|}{ Acute confusional syndrome, $\mathrm{n}(\%)$} & $50(34.5)$ & $25(47.2)$ & $25(27.2)$ & 2.39 & $1.17-4.85$ & 0.015 \\
\hline \multicolumn{2}{|l|}{ Others, $n(\%)$} & $145(22.2)$ & $30(10.1)$ & $115(32.2)$ & 0.23 & $0.15-0.36$ & $<0.001$ \\
\hline \multicolumn{2}{|c|}{ Non-clostridial diarrhea } & $4(4.3)$ & $3(10.7)$ & $1(1.6)$ & & & \\
\hline \multicolumn{2}{|c|}{ Mucocutaneous candidiasis } & $6(6.5)$ & $2(7.1)$ & $4(6.3)$ & & & \\
\hline \multicolumn{2}{|c|}{ Coagulopathy or other bleeding diathesis } & $1(1.1)$ & $1(3.6)$ & 0 & & & \\
\hline \multicolumn{2}{|c|}{ Thrombocytopenia } & $1(1.1)$ & 0 & $1(1.6)$ & & & \\
\hline \multicolumn{2}{|l|}{ Anaemia } & $5(5.4)$ & 0 & $5(7.8)$ & & & \\
\hline \multicolumn{2}{|c|}{ Electrolyte disorder } & $7(7.6)$ & $2(7.1)$ & $5(7.8)$ & & & \\
\hline \multicolumn{2}{|c|}{ Coronary syndrome } & $3(3.3)$ & $1(3.6)$ & $2(3.1)$ & & & \\
\hline \multicolumn{2}{|c|}{ Cardiac arrhythmia } & $3(3.3)$ & 0 & $3(4.7)$ & & & \\
\hline \multicolumn{2}{|l|}{ Seizures } & $1(1.1)$ & 0 & $1(1.6)$ & & & \\
\hline \multicolumn{2}{|c|}{ Acute urinary retention } & $9(9.8)$ & $3(10.7)$ & $6(9.4)$ & & & \\
\hline \multicolumn{2}{|c|}{ At least two of the above } & $52(56.5)$ & $15(53.6)$ & $37(57.8)$ & & & \\
\hline \multicolumn{2}{|c|}{ ICU admission due sepsis or any complication, $n(\%)$} & $10(1.53)$ & $7(2.36)$ & $3(0.84)$ & & & 0.198 \\
\hline
\end{tabular}

Significant $p$ values $(\leq 0.05)$ are highlighted in bold. Abbreviations: $\mathrm{Cl}$, confidence interval; ICU, Intensive Care Unit; OD, odds ratio; SC, Sepsis Code.

ICU admission

Phlebitis associated to intravenous catheters

Other complications

Heart failure

Acut e confusional syndrome

Complication outcomes

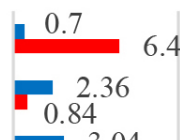

3.04
4.2

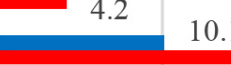

10.1

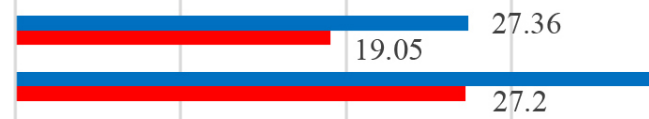

0

10

20

30

40

56.58

SC activated

SC not activated

\section{Figure 3 In-hospital complications. Data are expressed as percentages in the two cohorts.}

\section{SC: Sepsis Code.}

those reported in previous studies [52-54]. Study population was frail, comorbid and at high risk of readmission. Lower early mortality in SC group may be the main cause of readmission. Furthermore, data do not suggest readmissions were linked to treatment complications, but rather to a new sepsis episode.
Mortality. In the present study overall 28-day mortality rate in sepsis patients admitted to the IM ward was $32 \%$, similar to that described in studies that also included patients admitted to the ICU $[3,4,16,17,36,37]$. Focusing on the specific data from general wards, in these studies the percentages 


\begin{tabular}{|c|c|c|c|c|c|c|}
\hline Antibiotic related complications & side effe & & & & & \\
\hline Antibiotic related complications or side effects & TOTAL & SC activated (A) & SC not activated (B) & OR & $95 \% \mathrm{Cl}$ & p \\
\hline Toxicity, n (\%) & $43(6.6)$ & $16(5.4)$ & $27(7.6)$ & 0.69 & $0.36-1.32$ & 0.268 \\
\hline Type of toxicity, $n(\%)$ & & & & & & 0.076 \\
\hline Hypersensitivity reactions & 0 & 0 & 0 & & & \\
\hline Dermatologic reactions & $5(11.4)$ & $2(12.5)$ & $3(10.7)$ & & & \\
\hline Neurotoxicity & $5(11.4)$ & 0 & $5(17.9)$ & & & \\
\hline Gastrointestinal & $9(20.5)$ & $3(18.8)$ & $6(21.4)$ & & & \\
\hline Hepatic & $13(29.5)$ & $3(18.8)$ & $10(35.7)$ & & & \\
\hline Renal & $6(13.6)$ & $5(18.8)$ & $10(35.7)$ & & & \\
\hline Hematologic & $5(11.4)$ & $2(12.5)$ & $3(10.7)$ & & & \\
\hline Rhabdomyolysis & $1(2.3)$ & $1(6.3)$ & 0 & & & \\
\hline Severe toxicity, n (\%) & $5(11.6)$ & 0 & $5(18.5)$ & 1.22 & $1.02-1.46$ & 0.067 \\
\hline Multidrug-resistant bacterial colonization, $n(\%)$ & $66(10.14)$ & $33(11.15)$ & $33(9.3)$ & 1.23 & $0.74-2.05$ & 0.421 \\
\hline Multidrug-resistant bacterial infection, $\mathrm{n}(\%)$ & $53(81.5)$ & $23(69.7)$ & $30(93.8)$ & 0.15 & $0.03-0.76$ & 0.012 \\
\hline Colonization/infection diagnostic culture $1, n(\%)$ & & & & & & $<0.001$ \\
\hline Blood culture & $9(13.6)$ & 0 & $9(27.3)$ & & & \\
\hline Urine culture & $38(57.6)$ & $19(57.6)$ & $19(57.6)$ & & & \\
\hline Respiratory tract culture & $10(15.2)$ & $10(30.3)$ & 0 & & & \\
\hline Soft tissue exudate culture & $8(12.1)$ & $4(12.1)$ & $4(12.1)$ & & & \\
\hline Cerebrospinal fluid culture or analysis & $1(1.5)$ & 0 & $1(3)$ & & & \\
\hline Isolated microorganism in culture $1, \mathrm{n}(\%)$ & & & & & & 0.576 \\
\hline Methicillin-resistant Staphylococcus aureus & $6(9.1)$ & $2(6.1)$ & $4(12.1)$ & & & \\
\hline Linezolid-resistant coagulase-negative staphylococci & $1(1.5)$ & 0 & $1(3)$ & & & \\
\hline Ampicillin and vancomycin-resistance enterococci & $2(3)$ & $1(3)$ & $1(3)$ & & & \\
\hline Enterobacteriaceae producing ESBL, AmpC BL and carbapenemases & $2(3)$ & $2(6.1)$ & 0 & & & \\
\hline Multidrug-resistant Pseudomonas aeruginosa & $6(9.1)$ & $3(9.1)$ & $3(9.1)$ & & & \\
\hline Another multidrug-resistant microorganism & $1(1.5)$ & 0 & $1(3)$ & & & \\
\hline Clostridioides difficile & 0 & 0 & 0 & & & \\
\hline Colonization/infection diagnostic culture $2, n(\%)$ & & & & & & 0.027 \\
\hline Urine culture & $3(16.7)$ & $2(50)$ & $1(7.1)$ & & & \\
\hline Respiratory tract culture & $10(55.6)$ & 0 & $10(71.4)$ & & & \\
\hline Soft tissue exudate culture & $5(27.8)$ & $2(50)$ & $3(21.4)$ & & & \\
\hline Isolated microorganism in culture, $n(\%)$ & & & & & & 0.825 \\
\hline Methicillin-resistant Staphylococcus aureus & $2(22.2)$ & $1(25)$ & $1(20)$ & & & \\
\hline Enterobacteriaceae producing ESBL, AmpC BL and carbapenemases & $4(44.4)$ & $2(50)$ & $2(40)$ & & & \\
\hline Multidrug-resistant Pseudomonas aeruginosa & $2(22.2)$ & $1(25)$ & $1(20)$ & & & \\
\hline Other multidrug-resistant microorganisms & $1(11.1)$ & 0 & $1(20)$ & & & \\
\hline Clostridioides difficile diarrhea & $15(2.3)$ & $9(3.04)$ & $6(1.68)$ & 1.83 & $0.64-5.21$ & 0.248 \\
\hline
\end{tabular}

Significant $p$ values $(\leqslant 0.05)$ are highlighted in bold. Abbreviations: $\mathrm{Cl}$, confidence interval; OD, odds ratio; SC, Sepsis Code. 


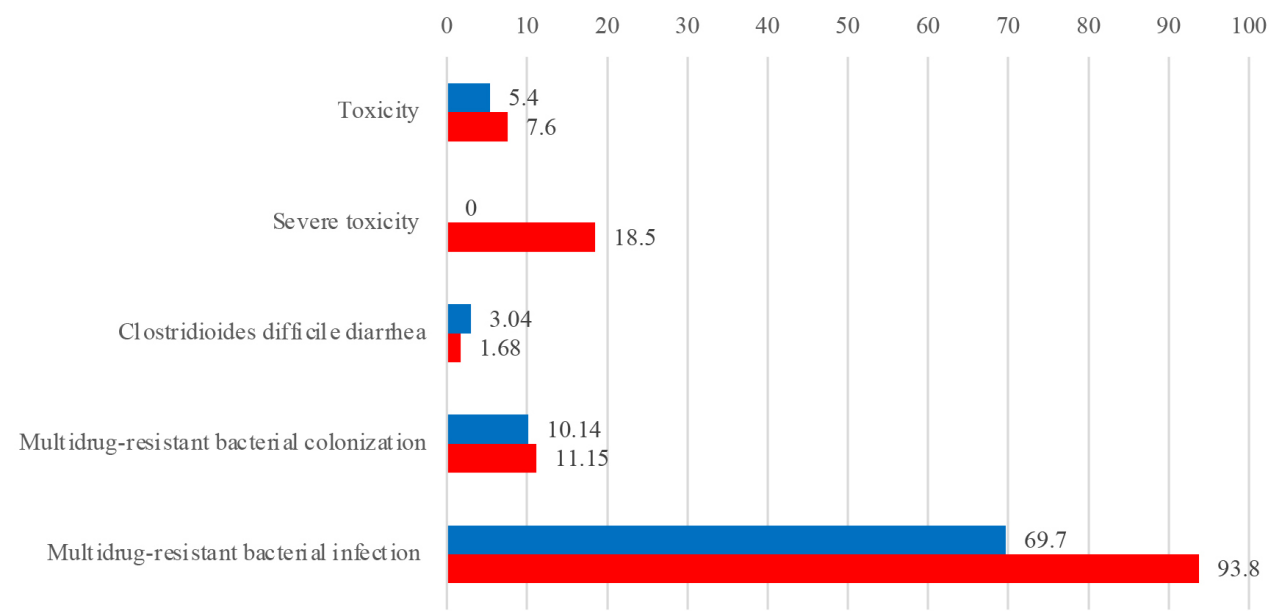

SC activated $\square C$ not activated

\begin{tabular}{l|l}
\hline Figure 4 & $\begin{array}{l}\text { Antibiotic related complications or side effects. Data are expressed as } \\
\text { percentages in the two cohorts. }\end{array}$
\end{tabular}

SC: Sepsis Code.

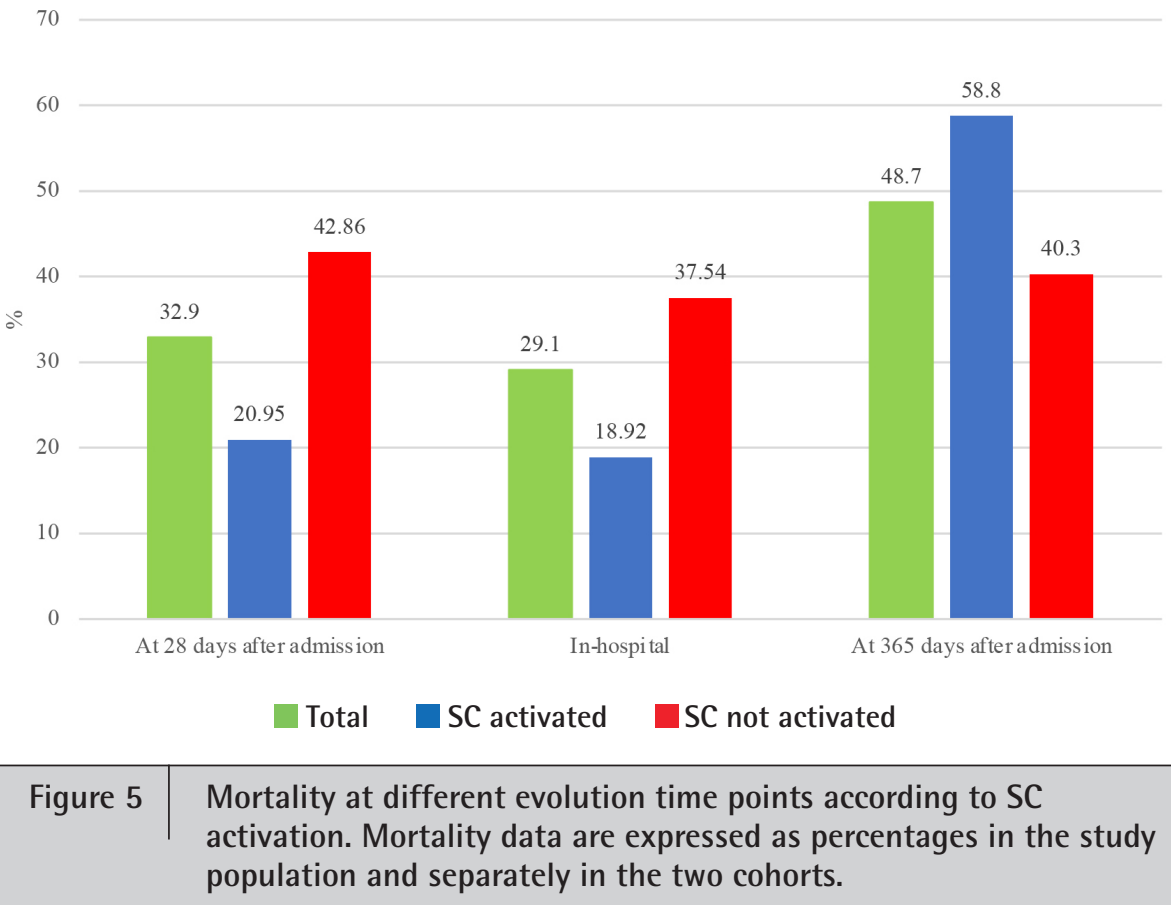

range between 12.8 and 26\%, which are closer to mortality data in Cohort A than in B. In these series, the lowest mortality values are found in non-severe sepsis; however, our rates do not distinguish groups with different severity of sepsis. Re- garding SC, our data show that activation results in a reduction of around a fifty percent in mortality of patients admitted to the IM ward.

The overall mortality rate at one year was $48.7 \%$, sub- 


\begin{tabular}{|c|c|c|c|c|c|c|c|}
\hline Table 6 & Hospital readmissions. & & & & & & \\
\hline \multicolumn{2}{|c|}{ Hospital readmissions } & TOTAL & SC activated (A) & SC not activated (B) & $\mathrm{OR}$ & $\mathrm{Cl} 95 \%$ & p \\
\hline \multicolumn{2}{|c|}{ Hospital readmission within 12 months after discharge, $n(\%)$} & $154(32.49)$ & $96(40)$ & $58(24.79)$ & 2.02 & $1.36-2.99$ & $<0.001$ \\
\hline \multicolumn{8}{|c|}{ Hospital readmission causes, $n(\%)$} \\
\hline \multicolumn{2}{|c|}{ New infection/sepsis } & $115(74.7)$ & $70(72.9)$ & $45(77.6)$ & 0.77 & $0.36-1.67$ & 0.519 \\
\hline \multicolumn{2}{|c|}{ Heart failure } & $14(9.1)$ & $8(8.3)$ & $8(10.3)$ & 0.78 & $0.25-2.39$ & 0.674 \\
\hline \multicolumn{3}{|c|}{ Other causes of hospital readmission, $\mathrm{n}(\%)$} & & & & & 0.233 \\
\hline \multicolumn{2}{|c|}{ Antibiotic toxicity } & $5(14.7)$ & $4(19)$ & $1(7.7)$ & & & \\
\hline \multicolumn{2}{|c|}{ Clostridioides difficile diarrhea } & $8(23.5)$ & $3(14.3)$ & $5(38.5)$ & & & \\
\hline \multicolumn{2}{|l|}{ Others } & $21(61.8)$ & $14(66.7)$ & $7(53.8)$ & & & \\
\hline
\end{tabular}

Significant $p$ values $(\leq 0.05)$ are highlighted in bold. Abbreviations: $\mathrm{Cl}$, confidence interval; $\mathrm{OR}, 0 \mathrm{dds}$ ratio; $\mathrm{SC}$, Sepsis Code.

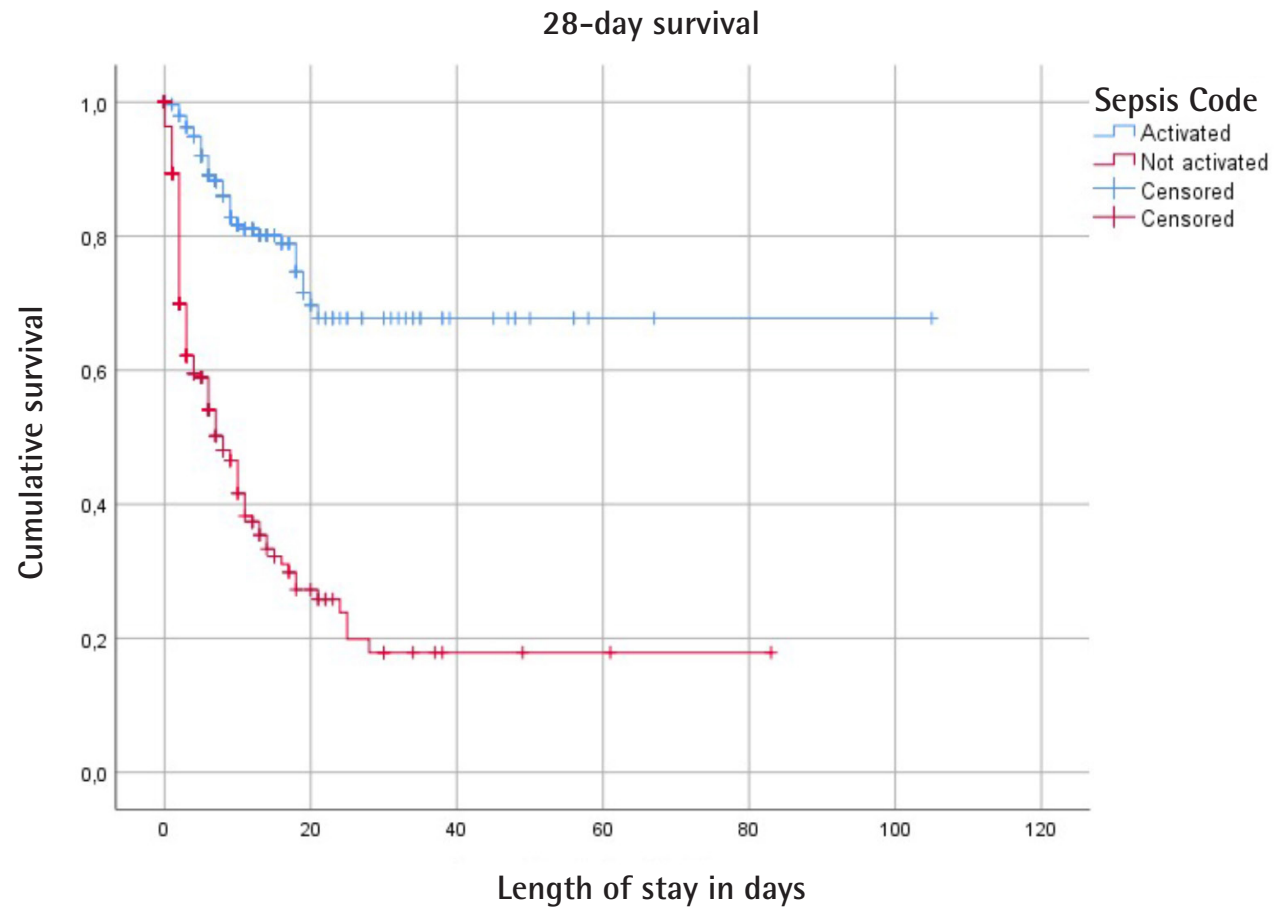

\begin{tabular}{l|l} 
Figure 6 & 28-day survival curves according to SC activation. Group A is represented
\end{tabular} in blue and $B$ in red. Censored refers to patients who survive. The survival rate was higher in the activated SC group ( $<<0.001$, log-rank test).

stantially higher than mortality rates reported in previously published studies $[30,31,55,56]$, which range between 21.7 and $31 \%$. This finding is likely to be related to the baseline characteristics of our population: higher mean age and a worse functional status than described series. Furthermore, these baseline conditions are the leading cause of long-term mortality related to sepsis $[15,30,32,33,35]$, regardless of the treatment implemented.
Remarkably, long-term mortality was higher in cohort A than in cohort B. This can be explained by the fact that the baseline characteristics are similar in both cohorts, and the implementation of SC bundles is not enough to combat the severity of morbidity due to sepsis. Female sex, aging, comorbidities, immunosuppression, severity of sepsis and respiratory infections, has been described as independent factors of long-term mortality in several studies [57-59], but these did 
not analyze the impact of standard treatment or SC bundles implementation.

Study limitations and strengths. The study has some limitations. It was a retrospective study and the quality of the results therefore depends on correct documentation. No verification of the sepsis diagnostic criteria was performed in group B. Patients were selected in the basis of their discharge diagnosis, and so we may have lost patients in which such term was not properly recorded (codification bias). We did not analyze profoundly readmissions data and so relevant information about evolution could have been lost.

Our study has also several strengths. It includes a large cohort of patients from IM unit and compares two concurrent cohorts considering SC activation.

Conclusions. Patients admitted with a diagnosis of sepsis in IM wards are elderly, with high comorbidity and functional disabilities. This fragility baseline situation is even greater in those patients managed without activating the SC.

More extensive microbiological diagnosis, more intensive treatment and adaptation of antibiotic therapy was performed in SC group. Nevertheless, a longer antibiotic treatment is also administered. This group has better infection control rate at 72 hours, less complications and lower short-term mortality. On the contrary, in-hospital stay, heart failure episode and readmissions increase in patients managed with this protocol.

Implementation of a SCP seems to be effective in improving short-term outcomes of patients admitted in IM units, although therapy should be tailored in an individual basis.

\section{ACKNOWLEDGEMENTS}

We would like to acknowledge the contribution of all members of "Sepsis Code Princesa" to the development of the hospital's programme and its legacy in improving the quality of life of patients.

\section{FUNDING}

None to declare

\section{CONFLICT OF INTEREST}

The authors declare no conflicts of interest.

\section{REFERENCES}

1 Angus DC, Linde-Zwirble WT, Lidicker J, Clermont G, Carcillo J, Pinsky MR. Epidemiology of severe sepsis in the United States: analysis of incidence, outcome, and associated costs of care. Crit Care Med 2001;29:1303-10. DOI: 10.1097/00003246-200107000-00002.

2 Padkin A, Goldfrad C, Brady AR, Young D, Black N, Rowan K. Epidemiology of severe sepsis occurring in the first $24 \mathrm{hrs}$ in intensive care units in England, Wales, and Northern Ireland: Crit Care Med

\section{3;31:2332-8. DOI: 10.1097/01.CCM.0000085141.75513.2B.}

3 Nguyen HB, Corbett SW, Steele R, Banta J, Clark RT, Hayes SR, et al. Implementation of a bundle of quality indicators for the early management of severe sepsis and septic shock is associated with decreased mortality*: Crit Care Med 2007;35:1105-12. D0I :10.1097/01.CCM.0000259463.33848.3D.

4 Angus DC, Barnato AE, Bell D, Bellomo R, Chong C-R, Coats TJ, et al. A systematic review and meta-analysis of early goal-directed therapy for septic shock: the ARISE, ProCESS and ProMISe Investigators. Intensive Care Med 2015;41:1549-60. DOI: 10.1007/s00134-0153822-1.

5 Seymour CW, Gesten F, Prescott HC, Friedrich ME, Iwashyna TJ, Phillips GS, et al. Time to Treatment and Mortality during Mandated Emergency Care for Sepsis. N Engl J Med 2017;376:2235-44. DOI: 10.1056/NEJMoa 1703058.

6 Bouza C, López-Cuadrado T, Saz-Parkinson Z, Amate-Blanco JM. Epidemiology and recent trends of severe sepsis in Spain: a nationwide population-based analysis (2006-2011). BMC Infect Dis 2014;14:3863. DOI: 10.1186/s12879-014-0717-7.

7 Álvaro-Meca A, Jiménez-Sousa MA, Micheloud D, Sánchez-Lopez A, Heredia-Rodríguez $M$, Tamayo $E_{1}$ et al. Epidemiological trends of sepsis in the twenty-first century (2000-2013): an analysis of incidence, mortality, and associated costs in Spain. Popul Health Metr 2018;16. DOI: 10.1186/s12963-018-0160-X.

8 Liu VX, Fielding-Singh V, Greene JD, Baker JM, Iwashyna TJ, Bhattacharya J, et al. The Timing of Early Antibiotics and Hospital Mortality in Sepsis. Am J Respir Crit Care Med 2017;196:856-63. DOI: 10.1164/rccm.201609-18480C.

9 Rhodes A, Evans LE, Alhazzani W, Levy MM, Antonelli M, Ferrer R, et al. Surviving Sepsis Campaign: International Guidelines for Management of Sepsis and Septic Shock. Crit Care Med 2017;45:486552. DOI: $10.1097 / C C M .0000000000002255$.

10 Gaieski DF, Edwards JM, Kallan MJ, Carr BG. Benchmarking the Incidence and Mortality of Severe Sepsis in the United States*: Crit Care Med 2013;41:1167-74. DOI: 10.1097/CCM.0b013e31827c09f8.

11 Palencia Herrejón E, González Del Castillo J, Ramasco Rueda F, Candel FJ, Sánchez Artola B, von Wernitz Teleki A, et al. [Consensus document for sepsis code implementation and development in the Community of Madrid]. Rev Espanola Quimioter Publicacion Of Soc Espanola Quimioter 2019;32:400-9. PMID: 31345006.

12 León Gil C, García-Castrillo Riesgo L, Moya Mir M, Artigas Raventós A, Borges Sa M, Candel González FJ, et al. Documento de Consenso (SEMES-SEMICYUC): Recomendaciones del manejo diagnóstico-terapéutico inicial y multidisciplinario de la sepsis grave en los Servicios de Urgencias hospitalarios. Med Intensiva 2007;31:37587. DOI: 10.1016/s0210-5691(07)74842-8

13 Levy MM, Evans LE, Rhodes A. The Surviving Sepsis Campaign Bundle: 2018 update. Intensive Care Med 2018;44:925-8. DOI: 10.1007/s00134-018-5085-0.

14 Mearelli F, Orso D, Fiotti N, Altamura N, Breglia A, De Nardo M, et al. Sepsis outside intensive care unit: the other side of the coin. Infection 2015;43:1-11. DOI: 10.1007/s15010-014-0673-6.

15 Martin GS, Mannino DM, Moss M. The effect of age on the develop- 
ment and outcome of adult sepsis. Crit Care Med 2006;34:15-21. DOI: 10.1097/01.ccm.0000194535.82812.ba.

16 Carmona-Torre F, Martinez-Urbistondo D, Landecho MF, Lucena JF. Surviving sepsis in an intermediate care unit. Lancet Infect Dis 2013;13:294-5. DOI:10.1016/S1473-3099(13)70072-0.

17 Rohde JM, Odden AJ, Bonham C, Kuhn L, Malani PN, Chen LM, et al. The epidemiology of acute organ system dysfunction from severe sepsis outside of the intensive care unit. J Hosp Med 2013;8:243-7. DOI: 10.1002/jhm.2012.

18 Rhee C, Gohil S, Klompas M. Regulatory Mandates for Sepsis Care Reasons for Caution. N Engl J Med 2014;370:1673-6. DOI: 10.1056/ NEJMp1400276.

19 A Randomized Trial of Protocol-Based Care for Early Septic Shock. N Engl J Med 2014;370:1683-93. DOI: 10.1056/NEJMoa1401602.

20 The PRISM Investigators. Early, Goal-Directed Therapy for Septic Shock - A Patient-Level Meta-Analysis. N Engl J Med 2017;376:2223-34. DOI: 10.1056/NEJMoa1701380.

21 Hershey TB, Kahn JM. State Sepsis Mandates - A New Era for Regulation of Hospital Quality. N Engl J Med 2017;376:2311-3. DOI: 10.1056/NEJMp1611928.

22 Klompas M, Calandra T, Singer M. Antibiotics for Sepsis-Finding the Equilibrium. JAMA 2018;320:1433. DOI: 0.1001/jama.2018.12179.

23 España, Ministerio de Sanidad SS e I, Boletín Oficial del Estado (España). Clasificacion Internacional de Enfermedades: 10a revisión : Modificación clinica : CIE.10.ES. Vol. 1, Vol. 1.. Madrid: Ministerio de Sanidad, Servicios Sociales e Igualdad : Boletín Oficial del Estado; 2018.

24 Sundararajan V, Henderson T, Perry C, Muggivan A, Quan H, Ghali WA. New ICD-10 version of the Charlson comorbidity index predicted in-hospital mortality. J Clin Epidemiol 2004;57:1288-94. DOI: 10.1016/j.jclinepi.2004.03.012.

25 Quan H, Li B, Couris CM, Fushimi K, Graham P, Hider P, et al. Updating and Validating the Charlson Comorbidity Index and Score for Risk Adjustment in Hospital Discharge Abstracts Using Data From 6 Countries. Am J Epidemiol 2011;173:676-82. DOI: 10.1093/aje/ kwq433.

26 Çıldır E, Bulut M, Akalın H, Kocabaş E, Ocakoğlu G, Aydın ŞA. Evaluation of the modified MEDS, MEWS score and Charlson comorbidity index in patients with community acquired sepsis in the emergency department. Intern Emerg Med 2013;8:255-60. DOI: 10.1007/ s11739-012-0890-x.

27 Oltean S, Țăţulescu D, Bondor C, Slavcovici A, Cismaru C, Lupșe M, et al. Charlson's weighted index of comorbidities is useful in assessing the risk of death in septic patients. J Crit Care 2012;27:370-5. DOI: 10.1016/j.jcrc.2011.08.021.

28 Cid-Ruzafa J, Damián-Moreno J. Valoración de la discapacidad fisica: el indice de Barthel. Rev Esp Salud Pública 1997;71:127-37. DOI: $10.1590 /$ S1135-57271997000200004.

29 Collin C, Wade DT, Davies S, Horne V. The Barthel ADL Index: a reliability study. Int Disabil Stud 1988;10:61-3. DOI: 10.3109/09638288809164103.

30 Henriksen DP, Pottegård A, Laursen CB, Jensen TG, Hallas J, Ped- ersen $C_{1}$ et al. Intermediate-term and long-term mortality among acute medical patients hospitalized with community-acquired sepsis: a population-based study. Eur J Emerg Med 2017;24:404-10. DOI: 10.1097/MEJ.0000000000000379.

31 Schmidt KF, Schwarzkopf D, Baldwin L-M, Brunkhorst FM, Freytag A,

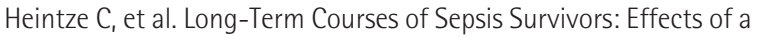
Primary Care Management Intervention. Am J Med 2020;133:381385.e5. DOI: 10.1016/j.amjmed.2019.08.033.

32 Zaccone V, Tosoni A, Passaro G, Vallone CV, Impagnatiello M, Li Puma $D D$, et al. Sepsis in Internal Medicine wards: current knowledge, uncertainties and new approaches for management optimization. Ann Med 2017:49:582-92. DOI: 10.1080/07853890.2017.1332776.

33 Vardi $M$, Ghanem-Zoubi NO, Bitterman $H_{1}$ Abo-Helo $N$, Yurin $V_{1}$ Weber $G$, et al. Sepsis in nonagenarians admitted to Internal Medicine departments: a comparative study of outcomes. OJM 2013;106:261-6. DOI: 10.1093/qjmed/hcs221.

34 Liu V, Lei X, Prescott HC, Kipnis P, Iwashyna TJ, Escobar GJ. Hospital readmission and healthcare utilization following sepsis in community settings: Healthcare Utilization after Sepsis. J Hosp Med 2014;9:502-7. DOI: 10.1002/jhm.2197.

35 Mazzone A, Dentali F, La Regina M, Foglia E, Gambacorta M, Garagiola E, et al. Clinical Features, Short-Term Mortality, and Prognostic Risk Factors of Septic Patients Admitted to Internal Medicine Units: Results of an Italian Multicenter Prospective Study. Medicine (Baltimore) 2016;95:e2124. DOI: 10.1097/MD.0000000000002124.

36 Esteban A, Frutos-Vivar F, Ferguson ND, Peñuelas O, Lorente JA, Gordo $F_{1}$ et al. Sepsis incidence and outcome: contrasting the intensive care unit with the hospital ward. Crit Care Med 2007;35:1284-9. DOI: 10.1097/01.CCM.0000260960.94300.DE.

37 Ghanem-Zoubi NO, Vardi M, Laor A, Weber G, Bitterman H. Assessment of disease-severity scoring systems for patients with sepsis in general internal medicine departments. Crit Care Lond Engl 2011;15:R95. DOI: 10.1186/cc10102.

38 Sango A, McCarter YS, Johnson D, Ferreira J, Guzman N, Jankowski CA. Stewardship Approach for Optimizing Antimicrobial Therapy through Use of a Rapid Microarray Assay on Blood Cultures Positive for Enterococcus Species. J Clin Microbiol 2013;51:4008-11. DOI: 10.1128/JCM.01951-13.

39 Campion M, Scully G. Antibiotic Use in the Intensive Care Unit: Optimization and De-Escalation. J Intensive Care Med 2018;33:64755. DOI: $10.1177 / 0885066618762747$.

40 Tabah A, Cotta MO, Garnacho-Montero J, Schouten J, Roberts JA, Lipman J, et al. A Systematic Review of the Definitions, Determinants, and Clinical Outcomes of Antimicrobial De-escalation in the Intensive Care Unit. Clin Infect Dis 2016;62:1009-17. D0I: 10.1093/ cid/civ1199.

41 Levy MM, Artigas A, Phillips GS, Rhodes A, Beale R, Osborn T, et al. Outcomes of the Surviving Sepsis Campaign in intensive care units in the USA and Europe: a prospective cohort study. Lancet Infect Dis 2012;12:919-24. DOI: 10.1016/S1473-3099(12)70239-6.

42 Stiermaier T, Herkner $H_{1}$ Tobudic S, Burgmann K, Staudinger T, Schellongowski $\mathrm{P}$, et al. Incidence and long-term outcome of sepsis on general wards and in an ICU at the General Hospital 
of Vienna: an observational cohort study. Wien Klin Wochenschr 2013;125:302-8. DOI: 10.1007/s00508-013-0351-1.

43 Pinilla Rello A, Huarte Lacunza R, Magallón Martínez A, Marrón Tundidor R, Martínez Álvarez R, Bustamante Rodríguez $E_{1}$ et al. Evaluación de los resultados de la implantación del Código Sepsis en el servicio de urgencias de un hospital terciario. J Healthc Qual Res 2020;35:281-90. DOI: 10.1016/j.jhqr.2020.06.008.

44 García-López L, Grau-Cerrato S, de Frutos-Soto A, Bobillo-De Lamo F, Cítores-Gónzalez R, Diez-Gutierrez F, et al. Impact of the implementation of a Sepsis Code hospital protocol in antibiotic prescription and clinical outcomes in an intensive care unit. Med Intensiva Engl Ed 2017;41:12-20. DOI: 10.1016/j.medine.2017.02.001.

45 De Waele JJ, Schouten J, Beovic B, Tabah A, Leone M. Antimicrobial de-escalation as part of antimicrobial stewardship in intensive care: no simple answers to simple questions-a viewpoint of experts. Intensive Care Med 2020;46:236-44. DOI: 10.1007/s00134019-05871-z.

46 Seok $H_{1}$ Jeon JH, Park DW. Antimicrobial Therapy and Antimicrobial Stewardship in Sepsis. Infect Chemother 2020;52:19-30. DOI: 10.3947/ic.2020.52.1.19.

47 Garnacho-Montero J, Gutiérrez-Pizarraya A, Escoresca-Ortega A, Corcia-Palomo $Y$, Fernández-Delgado $E_{1}$ Herrera-Melero $I_{\text {, et al. }}$ De-escalation of empirical therapy is associated with lower mortality in patients with severe sepsis and septic shock. Intensive Care Med 2014;40:32-40. DOI: 10.1007/s00134-013-3077-7.

48 Schuetz P, Wirz Y, Sager R, Christ-Crain M, Stolz D, Tamm M, et al. Effect of procalcitonin-guided antibiotic treatment on mortality in acute respiratory infections: a patient level meta-analysis. Lancet Infect Dis 2018;18:95-107. DOI: 10.1016/S1473-3099(17)30592-3.

49 Hranjec T, Rosenberger LH, Swenson B, Metzger R, Flohr TR, Politano $A D$, et al. Aggressive versus conservative initiation of antimicrobial treatment in critically ill surgical patients with suspected intensive-care-unit-acquired infection: a quasi-experimental, before and after observational cohort study. Lancet Infect Dis 2012;12:774-80. DOI: 10.1016/S1473-3099(12)70151-2.

50 Kumar A, Roberts D, Wood KE, Light B, Parrillo JE, Sharma S, et al. Duration of hypotension before initiation of effective antimicrobial therapy is the critical determinant of survival in human septic shock*: Crit Care Med 2006;34:1589-96. DOI: 10.1097/01. CCM.0000217961.75225.E9.

51 Gutiérrez Junco SM, Paipa Merchán AJ, Heredia Rodríguez M, Gómez Herreras JI, Tamayo Gómez E. The Resuscitation Bundle of the Surviving Sepsis Campaign Beyond Early Goal-Directed Therapy: What's Next? Crit Care Med 2015;43:e319-320. DOI: 10.1097| CCM.0000000000000960.

52 Goodwin AJ, Rice DA, Simpson KN, Ford DW. Frequency, Cost and Risk Factors of Readmissions among Severe Sepsis Survivors. Crit Care Med 2015;43:738-46. DOI: 10.1097/CCM.0000000000000859.

53 Prescott HC, Langa KM, Iwashyna TJ. Readmission Diagnoses After Hospitalization for Severe Sepsis and Other Acute Medical Conditions. JAMA 2015;313:1055. DOI: 0.1001/jama.2015.1410.

54 Shankar-Hari M, Saha R, Wilson J, Prescott HC, Harrison D, Rowan $K_{1}$ et al. Rate and risk factors for rehospitalisation in sepsis sur- vivors: systematic review and meta-analysis. Intensive Care Med 2020;46:619-36. DOI: 10.1007/s00134-019-05908-3.

55 Schuler A, Wulf DA, Lu Y, Iwashyna TJ, Escobar GJ, Shah NH, et al. The impact of acute organ dysfunction on long-term survival among sepsis survivors. Crit Care Med 2018;46:843-9. DOI: 10.1097/CCM.0000000000003023.

56 Storgaard M, Hallas J, Gahrn-Hansen B, Pedersen SS, Pedersen C, Lassen AT. Short- and long-term mortality in patients with community-acquired severe sepsis and septic shock. Scand J Infect Dis 2013;45:577-83. DOI: 10.3109/00365548.2013.786836.

57 Courtright KR, Jordan L, Murtaugh CM, Barrón Y, Deb P, Moore S, et al. Risk Factors for Long-term Mortality and Patterns of End-ofLife Care Among Medicare Sepsis Survivors Discharged to Home Health Care. JAMA Netw Open 2020;3. DOI: 10.1001/jamanetworkopen.2020.0038.

58 Francisco J, Aragão I, Cardoso T. Risk factors for long-term mortality in patients admitted with severe infection. BMC Infect Dis 2018;18. DOI: 10.1186/s12879-018-3054-4.

59 Linnér A, Sundén-Cullberg J, Johansson L, Hjelmqvist H, Norrby-Teglund A, Treutiger CJ. Short- and Long-Term Mortality in Severe Sepsis/Septic Shock in a Setting with Low Antibiotic Resistance: A Prospective Observational Study in a Swedish University Hospital. Front Public Health 2013;1. DOI: 10.3389/fpubh.2013.00051. 